\title{
A BRINCANÇA DOS EMBELÊCOS: VOZES POLÍTICAS E EPISTEMOLÓGICAS DOS SUBALTERNOS
}

\section{EL BRINCANÇA DE LOS EMBELÊCOS: VOCES POLÍTICAS Y EPISTEMOLÓGICAS DE LOS SUBALTERNOS}

\section{PLAYING OF EMBELECCOS: POLITICAL AND EPISTEMOLOGICAL VOICES OF THE SUBALTERNS}

\author{
Lindiane de SANTANA ${ }^{1}$ \\ Marizete LUCINI ${ }^{2}$
}

\begin{abstract}
RESUMO: Esse texto apresenta a brincança dos Embelêcos de Moita Bonita-SE como uma prática cultural que, na perspectiva dos brincantes, é subversiva e revolucionária. Inspiradas pela perspectiva do conhecimento pós-colonial que nos possibilita compreender que os subalternos só poderão falar quando falarem em sua própria língua, com seus sistemas explicativos, em sua própria cultura, propomos pensar sobre o impacto da invisibilização sistemática e naturalizada pelo colonialismo acadêmico em relação aos saberes da tradição oral. Para tanto, procedemos pela escuta profunda das narrativas dos mestres griôs. Estes, ao dizer o não-dito, provocam um descentramento da cultura tida de referência, produzindo efeitos epistemológicos de consequências políticas; portanto, um espaço de enunciação da voz dos subalternos e um lugar de resistência política.
\end{abstract}

PALAVRAS-CHAVE: Educação. Saberes. Tradição oral. Embelêcos.

RESUMEN: Este texto presenta el brincança de los Embelecos de Moita Bonita-SE como una práctica cultural que, desde la perspectiva de los jugadores, es subversiva y revolucionaria. Inspirados por la perspectiva del conocimiento poscolonial que nos permite comprender que los subalternos sólo podrán hablar, cuando hablan en su propio idioma, con sus sistemas explicativos, en su propia cultura, proponemos pensar sobre el impacto de la invisibilidad sistemática y naturalizada por el colonialismo académico en relación con los saberes de la tradición oral. Con este fin, procedemos escuchando profundamente las narrativas de los maestros Griots. Estos, al decir lo no dicho, provocan una descentralización de la cultura a la que se hace referencia, produciendo efectos epistemológicos de consecuencias políticas; por lo tanto, un espacio para la enunciación de la voz de los subalternos y un lugar de resistencia política.

PALABRAS CLAVE: Educación. Saberes. Tradición oral. Embelêcos.

1 Universidade Federal de Sergipe (UFS), São Cristóvão - SE - Brasil. Doutoranda no Programa de PósGraduação em Educação. Bolsista CAPES. ORCID: https://orcid.org/0000-0002-7320-8027. E-mail: lindyrion@gmail.com

${ }^{2}$ Universidade Federal de Sergipe (UFS), São Cristóvão - SE - Brasil. Professora Adjunta no Departamento de Educação e Docente Permanente no Programa de Pós-Graduação em Educação (PPGED/UFS). Doutora em Educação (UNICAMP). ORCID: https://orcid.org/0000-0003-1532-8968. E-mail: marizetelucini@gmail.com

RIAEE - Revista Ibero-Americana de Estudos em Educação, Araraquara, v. 15, n. esp. 3, p. 2521-2537, nov., 2020. E-ISSN: 1982-5587 
ABSTRACT: This paper introduces playing as Embelêcos from the municipality of Moita Bonita in the state of Sergipe, Brasil, as a cultural practice which, from the players 'perspective is subversive and revolutionary. Inspired by the perspective of the post-colonial knowledge, which allows us to understand that the subalterns can only speak in their own language, with their own explanatory systems, in their own culture, we propose thinking about the impact of systematic invisibilization, trivialized by the academic colonialism in relation to the knowledge of oral tradition. Therefore, we proceeded by listening deeply to the narratives of grio masters. When saying the unspoken, they provoke a decentralization of the culture seen as reference, producing epistemological effects of political consequences; thus, a space for enunciating the voice of subalterns and a place for political resistance.

KEYWORDS: Education. Knowledge. Oral tradition. Embelêcos.

\section{Introdução}

"Os Embelêco, é uma brincança da gente desse lugar". Então eu digo: "é uma brincadeira tradicional, né?". Ele responde: "Não, é uma brincança". Então pergunto: "mas se não é uma brincadeira... O que é uma brincança?". Ele responde: "nós não somos uma brincadeira normal, quando a gente faz essa brincança que é nossa, dos Embelêco tem um negócio diferente, sabe moça... é da alma da gente" (Diálogo com Mestre Pedro, em 2019).

"Os Embelêcos têm um sentido subversivo, revolucionário" (Griô Aprendiz Roberto, 2019).

Nestas prosas com o Mestre Griô ${ }^{3}$ Pedro e com o Griô Aprendiz ${ }^{4}$ Roberto, nos sentimos desafiadas a anunciar que a manifestação artístico-cultural dos Embelêcos não é uma brincadeira, é uma brincança, é a alma da gente. E a brincança é revolucionária, é subversiva. Palavras fortes que nos revelam que para além das palavras estão formas de pensar e sentir o mundo, constroem-se resistências, se produz alegria, música, na e pela Tradição Oral ${ }^{5}$. Música, alegria, brincança... subvertem, revolucionam.

Em uma noite de São Pedro seguimos viagem entre as ruas do povoado Capunga, ouvindo as fogueiras estalando em fogo, o cheiro de milho, os forrós, xote e baião se

${ }^{3}$ Griô ou Mestre(a) é todo(a) cidadão(ã) que se reconheça e seja reconhecido(a) pela sua própria comunidade como herdeiro(a) dos saberes e fazeres da tradição oral e que, através do poder da palavra, da oralidade, da corporeidade e da vivência, dialoga, aprende, ensina e torna-se a memória viva e afetiva da tradição oral, transmitindo saberes e fazeres de geração em geração, garantindo a ancestralidade e identidade do seu povo. A tradição oral tem sua própria pedagogia, política e economia de criação, produção cultural e transmissão de geração em geração (PACHECO, 2014, p. 64). No caso desta pesquisa os Mestres Griôs também são camponeses.

${ }^{4}$ O Griô Aprendiz é mais do que o lugar social e político de mediação. Ele é, antes de tudo, um arquétipo, ou seja, um personagem mítico, um encantado de alguém que doa sua corporeidade como lugar de registro, biblioteca viva e transmissão de saberes e fazeres de comunidades, grupos e povos de tradição oral, garantindo assim a continuidade da rede de transmissão oral (PACHECO, 2014, p. 73).

${ }^{5}$ Em linhas gerais, entendemos por tradição oral o universo de vivência dos saberes e fazeres da cultura de um povo, etnia, comunidade ou território que é criado e recriado, transmitido e reconhecido coletivamente através da oralidade, de geração em geração (LIMA; COSTA, 2014, p. 218).

RIAEE - Revista Ibero-Americana de Estudos em Educação, Araraquara, v. 15, n. esp. 3, p. 2521-2537, nov., 2020. E-ISSN: 1982-5587 
confundindo entre si. Em cada casa uma canção, pela estrada vários sons, bombas e rojões. Esse foi nosso primeiro encontro com o mestre Pedro. No dia de São Pedro. Foi neste encontro que escrevemos a escrevivência citada acima. $\mathrm{E}$ ali, percebemos que a pesquisa para a dissertação de mestrado $^{6}$ que se iniciara iria colorir as folhas brancas - A4, com margens, letras e espaçamentos definidos - de "alma da gente".

A proposta deste artigo é refletir sobre os resultados desta pesquisa em duas dimensões: 1. Epistemológica - como a produção de conhecimento sobre as trajetórias de vida dos mestres Griôs da Tradição Oral dos Embelêcos e a própria manifestação podem fortalecer epistemologias decoloniais e os conhecimentos diversos de resistência histórica de enfrentamento às matrizes coloniais da cultura e da educação; 2. Política - reflexões sobre a sistemática invisibilização das nossas vozes (subalternas) no campo da produção de conhecimento. Para tanto, evidenciaremos uma pequena caminhada etnográfica, na tentativa de apresentar a manifestação artístico cultural dos Embelêcos.

Inspiradas pela perspectiva do conhecimento pós-colonial de Spivak (2010), que afirma que os subalternos só poderão falar quando falarem em sua própria língua, seus sistemas explicativos, em sua própria cultura; pela perspectiva de educações de Brandão (2007) e pela perspectiva do conhecimento decolonial do mestre Griô Pedro e de Quijano (2000), trazemos um pouco da nossa experiência com a Tradição Oral para pensar sobre o impacto da invisibilização sistemática e naturalizada pelo colonialismo acadêmico em relação aos caminhos do fortalecimento das epistemologias e educações decoloniais, destacando aqui a tradição oral dos Embelêcos em Moita Bonita como um caminho de resistência.

\section{Não é uma brincadeira, é uma brincança}

Na noite de São Pedro de 20197, o termo "brincança" salta da boca do mestre Pedro, ao falar da manifestação artístico-cultural chamada Embelêco, e nos corrigiu por diversas vezes quando usamos o termo "brincadeira" para nos referirmos à "brincança" dos Embelêcos. Desde a infância ouvíamos as pessoas da própria comunidade chamarem os Embelêcos de "brincadeira", por isto, reproduzimos o termo. No entanto, para o mestre Pedro não se tratava de uma "brincadeira", mas de uma "brincança". Mas o que será uma "brincança"?

${ }^{6}$ Dissertação de mestrado defendida no Programa de Pós-graduação em Educação, na Universidade Federal de Sergipe, em 21 de fevereiro de 2019, com título: EMBELECANDO A EDUCAÇÃO: saberes griôs no povoado Capunga em Moita Bonita - Sergipe.

729 de junho de 2019.

RIAEE - Revista Ibero-Americana de Estudos em Educação, Araraquara, v. 15, n. esp. 3, p. 2521-2537, nov., 2020. E-ISSN: 1982-5587 
Analisando a palavra brincança morfologicamente, sua formação sugere brincar + -ança. A etimologia da palavra "brincar" é controversa. Possui origem alemã de blinken que significa "agitar-se"; ou do latim, que tem como radical "brinco" e raiz morfológica, vinculum, que significa vínculo (RODRIGUES; LEITE NUNES, 2010). O sufixo -ança, que se traduz no sentido de "ação, efeito, modo ou maneira" (LACOTIZ, 2006). Portanto, na língua portuguesa, podemos dizer que "brincança" refere-se a: 1. ação ou efeito de brincar, de divertir-se, constituindo-se em uma atividade de ligação com algo em si mesmo e/ou com o outro; 2. Maneira, modo ou forma de brincar. Contudo, na perspectiva do Mestre Pedro, "os Embelêco, é uma brincança da gente desse lugar". Ao penetrarmos no sentido êmico do termo, a "brincança" pode ser compreendida como a poética do brincar de um determinado grupo, do deixar-se brincar intuitivamente, do estabelecer vínculos com o brincar, permitindo-se encarnação de uma memória ancestral no corpo dos brincantes. Falamos de um conhecimento desde o coração e da alma. Na fala do Mestre Pedro: "nós não somos uma brincadeira normal, quando a gente faz essa brincança que é nossa, dos Embelêco, tem um negócio diferente, sabe moça... é da alma da gente" (informação verbal) (grifo nosso). Existe algo a mais que ele expressou como "da alma da gente" e nos foi possível sentir porque estávamos no diálogo, e absorvemos os gestos, os olhares e a corporalidade do mestre Pedro ao falar da brincança, compreendendo-a como um brincar vivencial e afetivo para além da racionalidade, mas que é "desse lugar", do território cultural. Pois é "da alma da gente”. A brincança carrega o indizível, pois ela é corpórea, é ancestral e é vivencial. Nesta mesma conversa que tivemos com o mestre Pedro, ele nos fala sobre a impossibilidade de aprender a tradição (referindo-se à manifestação artística-cultural dos Embelêcos) nos livros, apresentando-nos sua concepção vivencial da brincança. Procederemos na sequência para conhecer essa brincança anunciada.

O Embelêco é uma manifestação artístico-cultural fundada na Tradição Oral, que mistura religiosidade popular e o que é tido para o catolicismo como "profanidade". Esta manifestação é formada por homens e acontece no sábado de Aleluia ${ }^{8}$, na região de Moita Bonita (estado de Sergipe), principalmente no povoado Capunga, e em alguns povoados dos municípios circunvizinhos (Serra do Machado em Ribeirópolis, Alecrim em Malhador e Areias em Santa Rosa de Lima). A brincança inicia por volta das seis horas da manhã, quando, quem

${ }^{8}$ O Sábado de Aleluia é o sábado antes da Páscoa, portanto, um dia móvel no calendário cristão.

RIAEE - Revista Ibero-Americana de Estudos em Educação, Araraquara, v. 15, n. esp. 3, p. 2521-2537, nov., 2020. E-ISSN: 1982-5587 
"vai sair no Embelêco"" se reúne no rancho ${ }^{10}$, para que cada homem assuma seu personagem. Depois de prontos no rancho, os personagens e brincantes seguem em cortejo (figura 1) pelas ruas da cidade e povoados circunvizinhos, visitando residências e comércios; dançando, cantando e esperando uma contribuição em dinheiro das pessoas que assistem e interagem.

Figura 1 - $\mathrm{O}$ cortejo

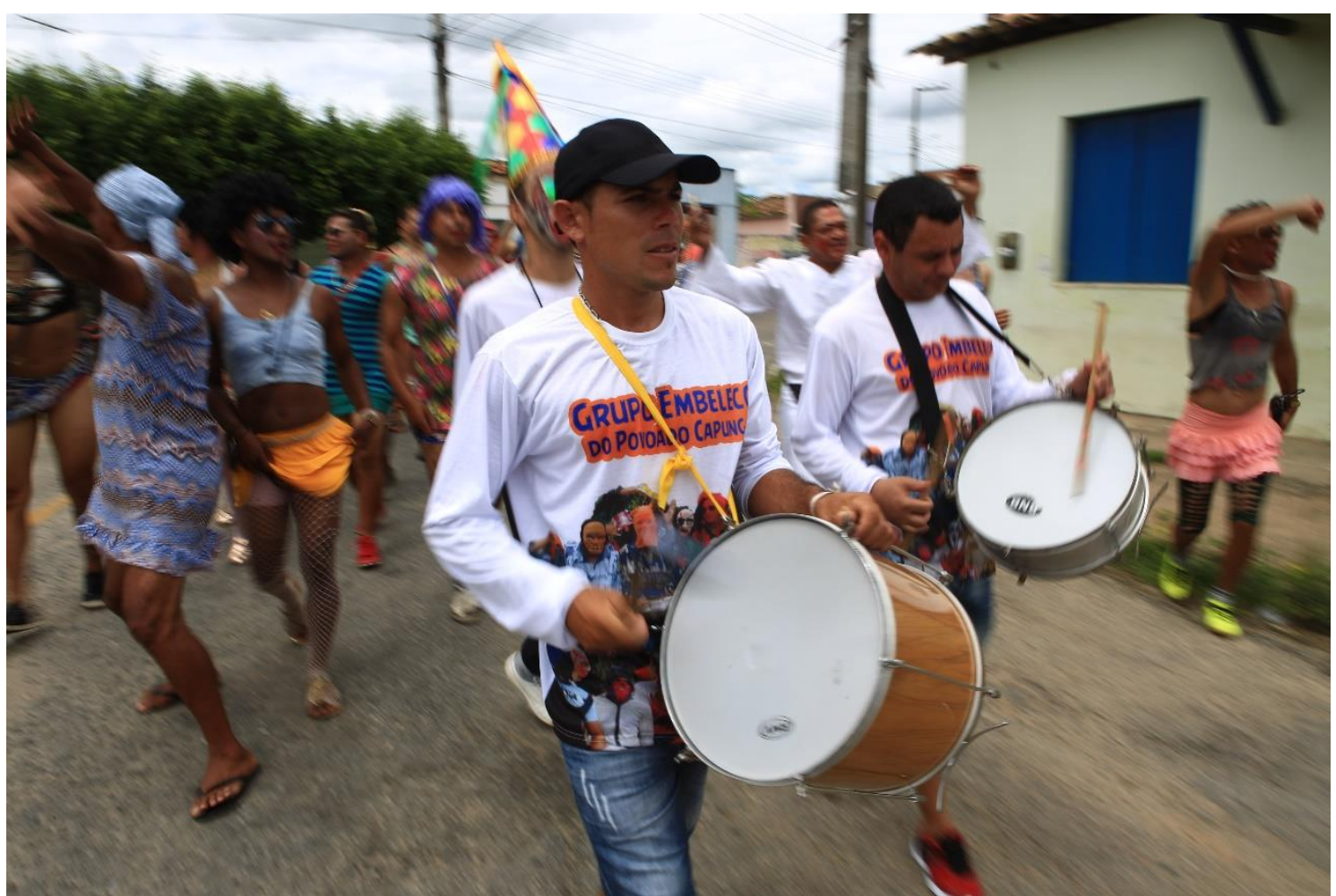

Fonte: Adilson Andrade (2017)

Para o deslocamento de um povoado a outro é usada uma "mercedinha" ${ }^{11}$. Neste deslocamento, é levado o boneco de pano (o Judas), em cima da "mercedinha" (figura 2), que simboliza Judas, o traidor de Jesus Cristo para os cristãos, que é ridicularizado durante o cortejo. No passado, há aproximadamente 30 anos atrás, este trajeto para os povoados que hoje é feito de "mercedinha" era feito em um animal, preferencialmente, o cavalo. Em hipótese alguma, segundo os brincantes, este trajeto poderia ser feito em um "jeguinho", pois se trata de um

9 "Sair no Embelêco" é um termo que a comunidade usa tentando descobrir quem irá ser personagem da tradição. Por exemplo: Fulano, você vai sair no Embelêco esse ano? Essa pergunta sempre é um mistério que nunca deve ser respondido.

${ }^{10}$ Rancho é o nome do local que todos individualmente combinam com o Mestre Griô, que normalmente é o palhaço, para se produzirem. As identidades dos judeus/caretas são ocultas. Por tradição, ninguém deve saber quem são eles, só entre eles mesmos.

${ }^{11}$ Caminhão de pequeno porte. Tem o apelido de "mercedinha" na comunidade devido à marca da Mercedes-Benz. Além de expor o boneco do Judas, a mercedinha é utilizada para transportar os Embelêcos até as outras cidades e povoados.

RIAEE - Revista Ibero-Americana de Estudos em Educação, Araraquara, v. 15, n. esp. 3, p. 2521-2537, nov., 2020. E-ISSN: 1982-5587 
animal abençoado, sendo o responsável por transportar Cristo para a entrada triunfal em Jerusalém, antes de sua morte. O Judas, na perspectiva dos embelêcados, não é digno de subir no animal abençoado, o jegue.

Figura 2 - Embelêcos na Mercedinha

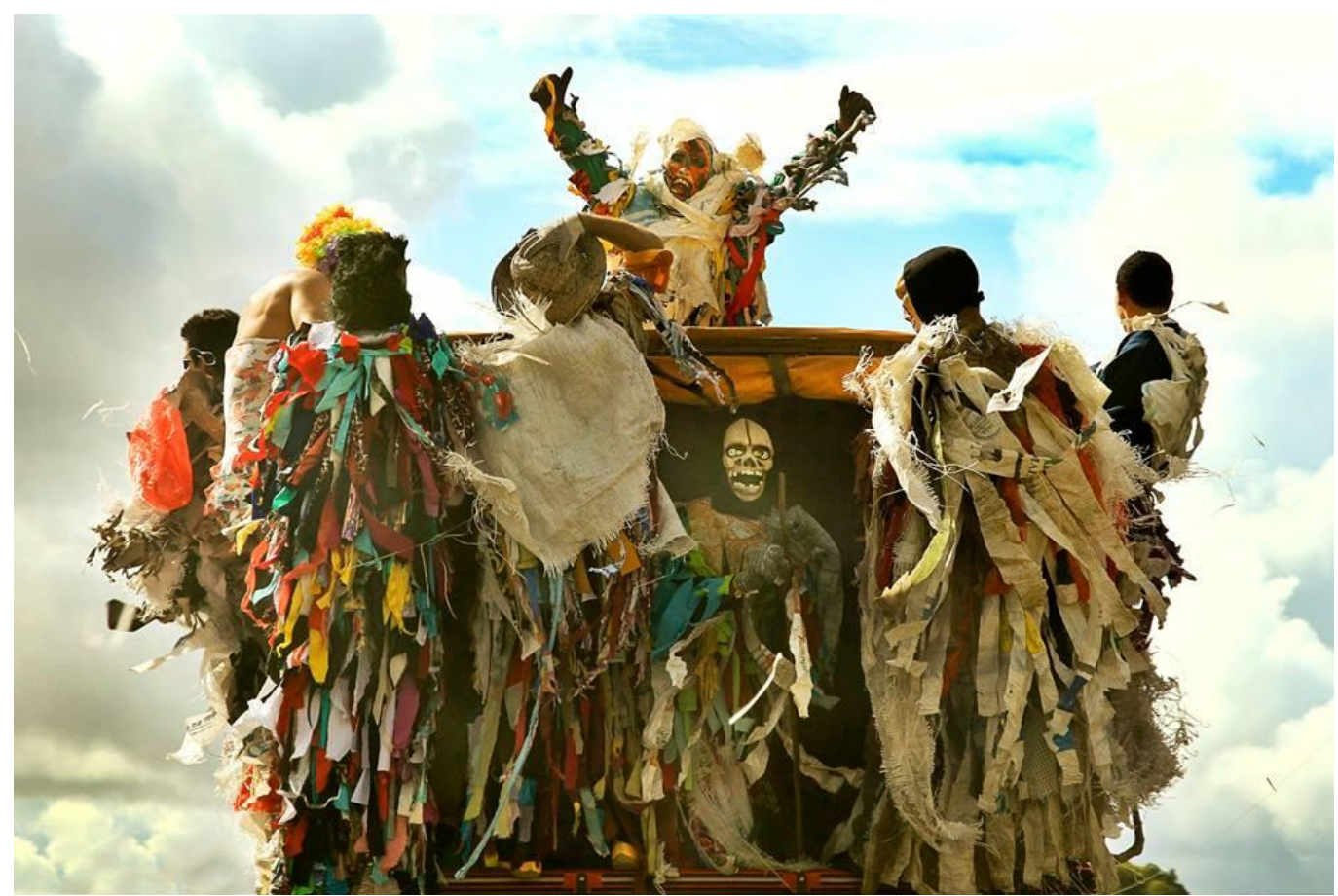

Fonte: Silvia Marcia de Andrade (2015)

$\mathrm{Na}$ volta do cortejo, ao entardecer, o Judas é hasteado em um madeiro, ficando exposto o restante da tarde para ser ridicularizado pela comunidade do Capunga. No início da noite, os Embelêcos se reúnem com a comunidade para leitura do testamento e a queima de Judas na fogueira. Então é lido seu testamento em cordel, depois o Judas é queimado (figura 3). No início da noite, a brincança é finalizada com a queima do Judas. 
Figura 3 - A queima do Judas

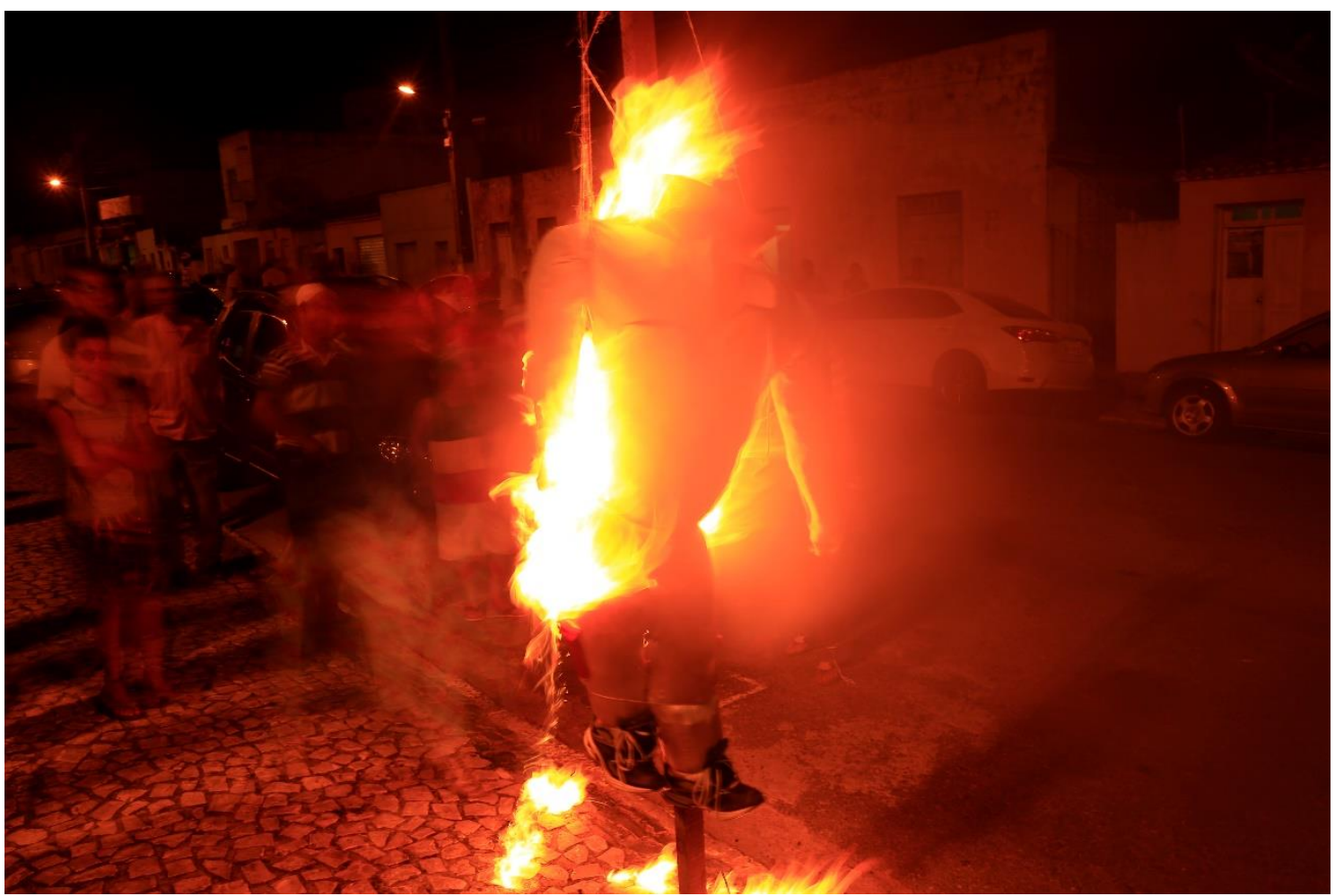

Fonte: Adilson Andrade (2016)

Durante todo o ritual de cortejo até a queima do Judas, alguns personagens que realizam o cortejo se apresentam em um teatro de rua dançante. Apresentamos aqui os personagens principais: os caretas (também chamados de velhos, judeus, embelecos), o palhaço, os gerentes, as putinhas e os músicos ${ }^{12}$.

O careta personagem é o mais independente do grupo. Na figura 2 podemos vê-los em cima do caminhão, vestindo roupas de retalhos. Ele possui a liberdade de não estar junto ao cortejo que segue pelas ruas. Anda pelas ruas, sítios e vielas solitário, pedindo dinheiro e assustando as pessoas, principalmente, as crianças. Com chicote nas mãos, amedronta quem não lhe der dinheiro, ameaçando com chibatadas. Dentro da manifestação, ser careta é o personagem mais concorrido e todos os garotos querem vestir-se de careta. Entre os assuntos levantados com os mestres sobre o motivo da concorrência para vivenciar o personagem, eles indicam que o primeiro aspecto é o dinheiro que os caretas recebem individualmente e não precisa ser dividido com o grupo. O outro motivo é o fato de que o careta tem sua identidade

${ }^{12}$ Além destes personagens existem outros que são criados e recriados todos os anos. Alguns, pelo uso anual tornam-se já parte da brincança, como por exemplo: o padre, a cigana, a noiva, a veia do buchão (mulher grávida), a bruxa, a morte, o motoqueiro fantasma e etc. É de livre criação cada personagem.

RIAEE - Revista Ibero-Americana de Estudos em Educação, Araraquara, v. 15, n. esp. 3, p. 2521-2537, nov., 2020. E-ISSN: 1982-5587 
preservada, visto que usa máscaras, o que gera dificuldades para encontrar os outros personagens, porque todos os garotos querem se vestir de velho.

O palhaço (figura 4) é o mestre da manifestação, apesar de nos Embelêcos a figura do mestre não ser destacada das demais, considerando que nesta manifestação cultural não existe uma hierarquia, ou saberes superiores de um líder. Existe a compreensão de que todos os mais velhos que representam algum personagem são responsáveis por transmitir para os mais novos os gestos, os trejeitos daquele personagem que ele carrega todos os anos.

Figura 4 - O Palhaço

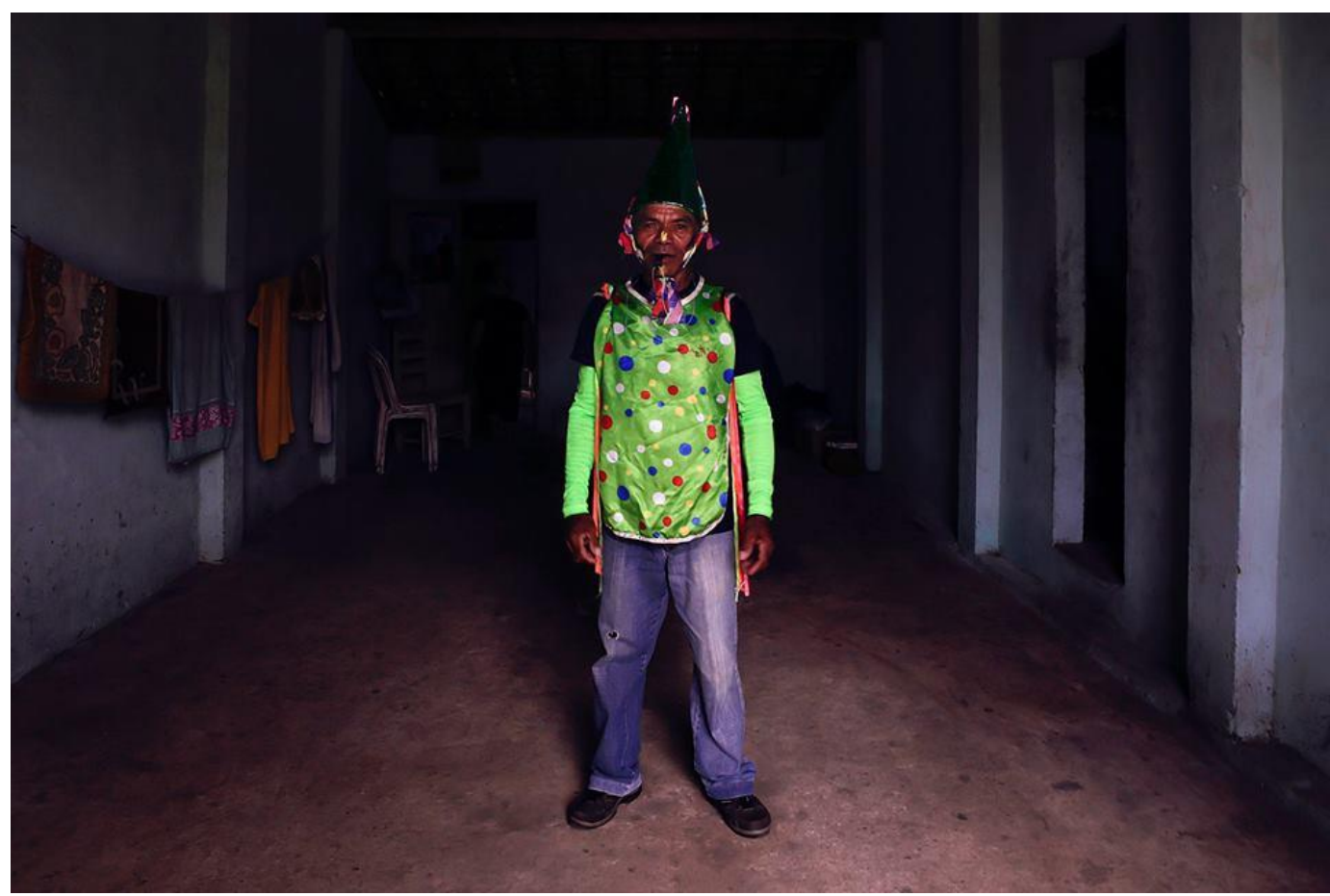

Fonte: Adilson Andrade (2019)

O Palhaço, como um mestre da manifestação, geralmente é o mais velho, mas ultimamente temos visto alguns novos palhaços aparecerem, principalmente após a morte dos mais velhos. Ele é quem cria os versos (músicas), também é ele quem organiza os horários, os lugares que farão o cortejo, o rancho para se encontrar, os figurinos. Enfim, tudo na manifestação passa por ele, inclusive a escolha de quem vai ocupar cada papel (personagem). Quando se aproxima o final da quaresma, quem deseja brincar, principalmente de careta ${ }^{13}$, procura o palhaço secretamente para combinar os horários e a construção do figurino.

${ }^{13}$ Devido à necessidade de sigilo.

RIAEE - Revista Ibero-Americana de Estudos em Educação, Araraquara, v. 15, n. esp. 3, p. 2521-2537, nov., 2020. E-ISSN: 1982-5587 DOI: https://doi.org/10.21723/riaee.v15iesp3.14455 
Os gerentes (figura 5) acompanham o palhaço junto com os músicos, sua função principal é marcar o andamento da música com os apitos que carregam. $\mathrm{O}$ apito dos gerentes determina o andamento da música, dos versos e dos brincantes, visto que os pés, em dança, acompanham este andamento.

\section{Figura 5 - O Gerente}

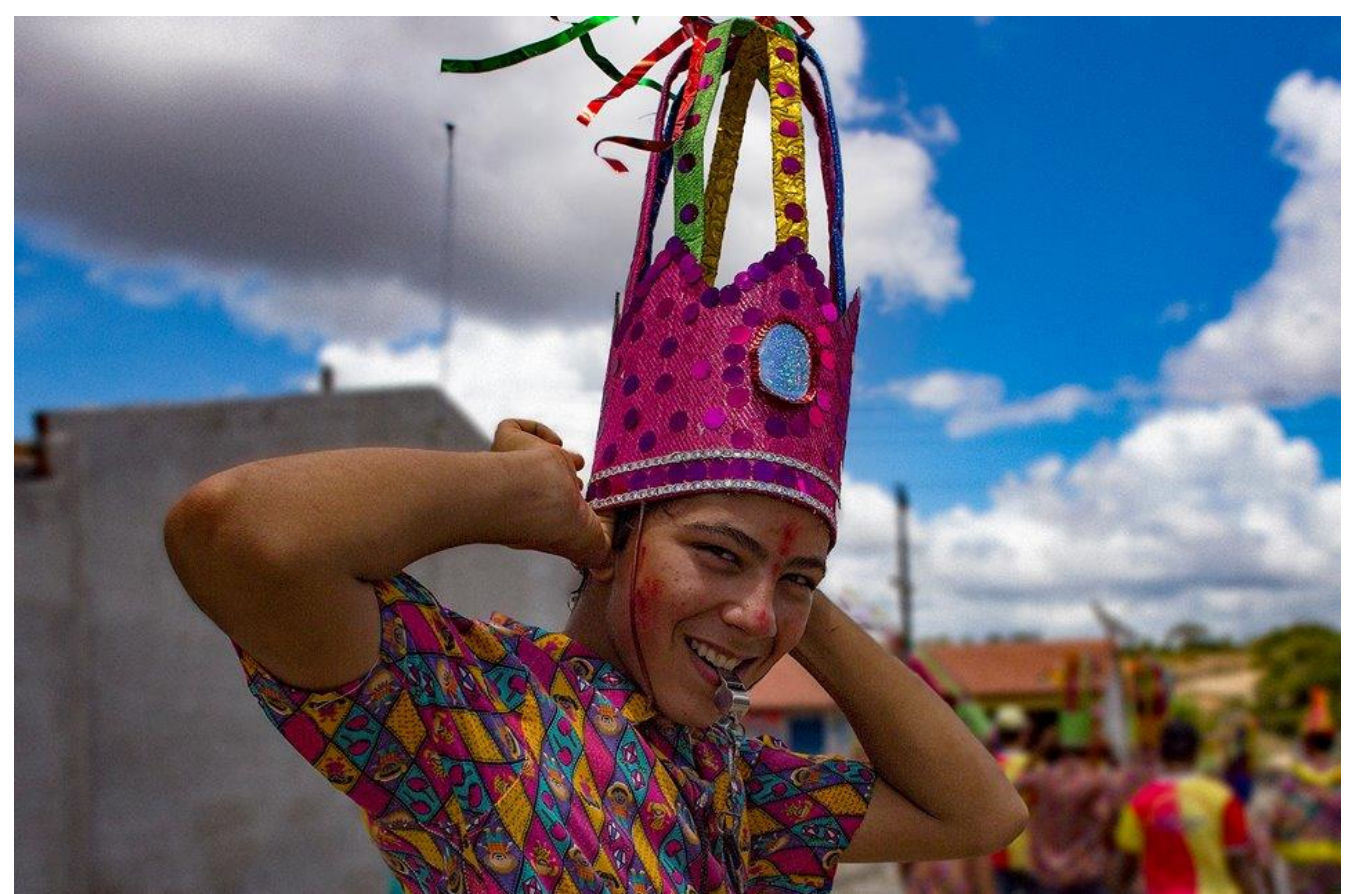

Fonte: Adilson Andrade (2016)

Os gerentes andam em grupos de seis pessoas, formando três duplas, dispostos em um corredor onde o palhaço passeia dançando e cantando durante o cortejo. Em sua função, os gerentes do lado esquerdo marcam o andamento da música em compasso binário simples, enquanto os gerentes do lado direito fazem o tempo e contratempo, subdividindo o compasso. O apito do gerente é o coração da música da brincança dos Embelêcos, fazendo a base musical rítmica para os músicos realizarem uma subdivisão em cima, para o palhaço e todos dançarem e cantarem (puxar verso).

As putinhas (podem ser visualizadas na figura 1, atrás dos músicos). São homens vestidos de mulher, que saem junto ao cortejo animando e paquerando os homens, principalmente os casados. Elas se sentam no colo dos rapazes, dão beijo na boca, sujam de batom e andam com roupas sensuais e provocantes etc.

Os músicos (visualizados na figura 1), que são conhecidos como os batedores de caixinha e tambor, podem estar vestidos de gerentes, como é muito comum, ou simplesmente 
estarem com roupas do cotidiano. A música desempenha um importante papel na brincança dos Embelêcos. Ela possui a função de dar e preservar o ritmo do cortejo/espetáculo, estando presente do início ao fim da brincança. A letra dos versos musicados remete aos mitos, histórias, memórias e principalmente ao cotidiano da comunidade. Fofocas e características físicas das pessoas da comunidade também são expostas nos versos, no intuito de divertir, o que por vezes causa atrito entre os membros da comunidade. Através da música, os brincantes seguem em cortejo, com danças e versos.

Além destes personagens aqui descritos, a manifestação é dinâmica e fluída. Anualmente, ela é reinventada no próprio movimento da brincança, podendo aparecer ciganas, bruxas, padres, fazendeiros, entre outros personagens. Cada personagem deste carrega em si um tom crítico sobre as opressões e libertações que eles trazem para a comunidade. Se, de alguma maneira, a comunidade não vê com bons olhos a figura de um fazendeiro, um político ou um líder religioso dentro da comunidade, ele será representado nas ruas, no Sábado de Aleluia, e será queimado como um Judas (um traidor).

\section{Os mestres da brincança e suas histórias de vida}

Para Pacheco (2014), um mestre Griô é todo aquele que:

[...] se reconheça e seja reconhecido(a) pela sua própria comunidade como herdeiro(a) dos saberes e fazeres da tradição oral e que, através do poder da palavra, da oralidade, da corporeidade e da vivência, dialoga, aprende, ensina e torna-se a memória viva e afetiva da tradição oral, transmitindo saberes e fazeres de geração em geração, garantindo a ancestralidade e identidade do seu povo. A tradição oral tem sua própria pedagogia, política e economia de criação, produção cultural e transmissão de geração em geração (PACHECO, 2014, p. 64).

No entanto, na manifestação artístico-cultural dos Embelêcos essa figura é composta por vários mestres de uma mesma tradição oral, pois cada personagem é mestre de seu personagem. Existe aquele mestre que guarda no corpo a memória ancestral do que é ser palhaço nos Embelêcos, do que é ser velho, do que é ser as putinhas etc. Quem se coloca como aprendiz griô, coloca-se como aprendiz da história de vida e de uma linguagem vivencial, corporal e oral de um trabalhador velho e ancestral (PACHECO, 2014).

A história de vida encontra-se no modelo de ação pedagógica da Pedagogia Griô (PACHECO, 2017), porque ela é uma das linguagens com as quais os sábios da oralidade (velhos Griôs) transmitem seus conhecimentos. Para Pacheco (2014, p.41), a história de vida costura o fio entre a minha história e a história de meu povo, e é esse fio que a Pedagogia Griô 
procura reatar. Assim, tudo que um velho griô ${ }^{14}$ escreve na oralidade é marcado pela sua trajetória de vida e condição ancestral.

Para Pereira (2014), a própria narração da história de vida dos sujeitos envolvidos na pesquisa é uma ferramenta para transmissão dos saberes, crenças, valores, etc. Durante o desenvolvimento da pesquisa que este trabalho expõe, foi notável a importância que os mestres deram à história de vida de cada um. Percebemos essa importância no silêncio que pairava no salão enquanto um mestre narrava sua história ${ }^{15}$. Ao fazerem a escolha para a oficina, os mestres escolheram iniciar contando suas histórias de vida. A história de vida é importante como método de coleta, mas para além disso ela é o próprio caminhar griô. Assim, os mestres transmitem suas histórias e estórias de geração a geração.

Através da história de vida que cada mestre griô se propõe a nos contar, remetemos a memória como matéria prima para a pesquisa. Esta memória da história de vida dos griôs, compreendemos como uma memória individual, que é aquela que se refere às vivências e experiencias pessoais de cada indivíduo, mas que incorpora elementos da memória coletiva ${ }^{16}$ de um dado grupo social no qual o indivíduo convive. Entendemos a memória como a capacidade humana de guardar fatos e experiências do passado e transmiti-los às novas gerações através de diferentes suportes empíricos, que podem ser eles a voz, uma música, uma fotografia, um quadro, um cordel etc. No entanto, as memórias que os mestres dos Embelêcos guardam podem ser compreendidas também como aquelas que Pollack (1989) designa como memórias subterrâneas. Memórias que estão guardadas nos grupos marginalizados, subalternizados da sociedade; nestas memórias encontram-se outras versões de uma dada história, "se opõem à memória oficial"' (POLLACK, 1989, p. 4), ou seja, essa é a memória que não ocupa os museus, que não está nos monumentos.

Essas memórias subterrâneas estão guardadas no seio das famílias, das comunidades e de grupos oprimidos. Para Pollack (1989, p. 4), elas "prosseguem seu trabalho da subversão, no silêncio e de maneira imperceptível afloram em momentos de crise em sobressaltos bruscos e exacerbados". Ele utiliza de três exemplos para falar do silêncio sobre o passado: o primeiro deles foi sobre o stalinismo, o segundo sobre os judeus nos campos de concentração nazista e o terceiro sobre o recrutamento forçado de trabalhadores alsacianos e lorenos para a Segunda

\footnotetext{
${ }^{14}$ Sinônimo de Mestre Griô.

${ }^{15}$ Durante o desenvolvimento desta pesquisa foi realizada uma Oficina com os mestres griôs dos Embelêcos, elaborada do início ao fim pelos mestres, a partir de nossa solicitação de que nos proporcionassem essa experiência sobre suas histórias de vida.

${ }^{16}$ Compreendemos conforme Pollack (1989, p. 3) como "uma memória estruturada em hierarquias e classificações, uma memória também que, ao definir o que é comum a um grupo e o que o diferencia dos outros, fundamenta e reforça os sentimentos de pertencimento e as fronteiras socioculturais".
}

RIAEE - Revista Ibero-Americana de Estudos em Educação, Araraquara, v. 15, n. esp. 3, p. 2521-2537, nov., 2020. E-ISSN: 1982-5587 
Guerra Mundial. Nestes silêncios que se parecem com esquecimento, ressurgem das cinzas as memórias subalternas, como memória viva. Essas memórias eram "não-ditas", como um ato de proteção.

Por conseguinte, existem nas lembranças de uns e de outros zonas de sombra, silêncios, "não-ditos". As fronteiras desses silêncios e "não-ditos" com o esquecimento definitivo e o reprimido inconsciente não são evidentemente estanques e estão em perpetuo deslocamento (POLLACK, 1989, p. 8).

Neste importante papel de reter as memórias na intenção de passá-las de geração a geração, existe a figura social do guardião/guardiã de memória. Para a Pedagogia Griô, o mestre e o Griô aprendiz são guardiões da memória de seu povo. E nesse processo, o aprendiz griô doa seu corpo para guardar a memória viva de uma linguagem corporal, vivencial, oral e ancestral. Aos guardiões de memória cabe a missão de transmitir para as próximas gerações os fatos, as vivências, a ancestralidade que o corpo carrega como memória e que são imprescindíveis para a sobrevivência do grupo.

\section{O encanto que falta à escola}

Em meio às vivências, uma pergunta nos ocorre: poderemos dizer que o que estes mestres fazem NÃO é Educação? Não, não podemos. Eles encantam e ensinam coisas que ultrapassam a escrita, ensinam a oralidade. Para além dos saberes artísticos e culturais que a construção da manifestação promove ${ }^{17}$, as crianças se encantam com a manifestação, há o saber do encantamento.

Por que a ausência em nossas escolas de manifestações como esta, que é a alma da gente? A única escola no povoado de onde a manifestação pertence não trabalha com a manifestação em nenhum momento e não a menciona no currículo. Para Simas e Rufino (2020), a colonização produziu o desencantamento, e a falta deste encantamento na educação é um reflexo do desencantamento da vida. Os autores citam o encantamento

[...] como uma capacidade de transitar nas inúmeras voltas do tempo, invocar espiritualidades de batalha e de cura, primar por uma política e educação de base comunitária entre todos os seres e ancestrais, inscrever o cotidiano como rito de leitura e escrita em diferentes sistemas poéticos e primar pela inteligibilidade dos ciclos é luta frente ao paradigma de desencanto instalado aqui. Ou seja, o encante é fundamento político que confronta as limitações da

${ }^{17}$ Para saber mais sobre os saberes revelados pela manifestação, ver: SANTANA, Lindiane de. EMBELECANDO A EDUCAÇÃO: saberes griôs no povoado Capunga em Moita Bonita - Sergipe. 2020.

RIAEE - Revista Ibero-Americana de Estudos em Educação, Araraquara, v. 15, n. esp. 3, p. 2521-2537, nov., 2020. E-ISSN: 1982-5587 
chamada consciência das mentalidades ocidentalizadas (SIMAS; RUFINO, 2020, p. 6).

A ausência dos Embelêcos na escola diz sobre o modelo de colonização do pensamento a nós imposto. Desta forma, os saberes considerados aceitos, não são os nossos, são os deles, os eurocentrados. Munsberg e Ferreira da Silva (2018) apontam a educação intercultural como um impulsionador da descolonização, apresentando a importância da escola e do currículo neste processo educacional de abordagens plurais; "remetendo para a construção de uma "sociedade outra" mediante a superação de velhos discursos, de estruturas excludentes e de posturas discriminatórias" (MUNSBERG; FERREIRA DA SILVA, 2018, p.140).

Os Embelêcos cativam os jovens de uma forma que a escola ainda não cativou. Para ouvir o mestre, as crianças param para aprender, ficam atentas às estórias e histórias. Analisando a educação escolar indígena Pataxó, Silva (2012), aponta a interculturalidade como um impulso para criação de um novo sentido e perfil para esta escola. Instituição, que é fruto de um processo colonial, que, entre outras coisas, é destinada também ao controle dos corpos. A presença destes outros saberes, que também são corporais, pode representar uma ameaça para este sistema colonial de desencantamento da vida. De acordo com Alves e Rocha (2019), a educação intercultural permite além da compreensão de sua própria cultura, a compreensão da cultura do outro, criando a possibilidade de construção de um outro processo educativo, fundamentado em valores de alteridade, tolerância e reciprocidade. Será que o que falta para as crianças, não é só um pouco da alma da gente?

De acordo com Pacheco e Eyng (2020), ao observar a eficácia das políticas e mecanismos de normatização dos processos coloniais na América Latina, ele e ela apontam para a possibilidade da educação intercultural ser uma via para construção de processos decoloniais. Essa possibilidade nos coloca diante de uma potência, a de pensar e dialogar com outras epistemologias, outras formas de conhecer, nos aproximando de nós mesmos em nosso viver e fazer resistência. E a pergunta que nos desafia nessa reflexão é pensar sobre o que será que dialogar com nossa própria língua e sistemas explicativos poderia produzir na escola?

\section{Vozes políticas e epistemológicas dos subalternos}

Porque mesmo que queimem a escrita, não queimarão a oralidade. Mesmo que queimem os símbolos, não queimarão os significados. Mesmo queimando nosso povo, não queimarão a ancestralidade (SANTOS, Antônio Bispo, 2019, p. 33). 
Ao falarmos da brincança dos Embelêcos nos situamos numa perspectiva epistemológica camponesa, decolonial (QUIJANO, 2000), fundamentada na Tradição Oral, em que praticamos uma escuta consciente de que, para uma boa parte de nós, musicistas, camponeses, manifestantes de Tradição Oral, sobretudo no interior de Sergipe, do Nordeste do Brasil, conhecimento, resistência, espiritualidade e brincança não são excludentes. Pelo contrário, são nutridos um pelo outro. Assim, os subalternos falam em sua própria língua.

Para Spivak (2010, p. 12), o subalterno é aquele que pertence "às camadas mais baixas da sociedade constituídas pelos modos específicos de exclusão dos mercados, da representação política e legal, e da possibilidade de se tornarem membros plenos no estrato social dominante". Entendemos com Aníbal Quijano (2010) que estes mesmos subalternos, nas relações de poder, são racializados. E que essa racialização, internaliza a subalternidade nas estruturas subjetivas do colonizado. Que, com efeito, produz e perpetua a sujeição dos saberes/conhecimentos, sujeição de uma raça em relação à outra, a sujeição da mulher em relação ao homem e todo esse padrão de pensamento onde sempre existe o colonizado e o colonizador. Dessa forma, você pode estar se perguntando por que utilizamos Spivak (2010) para falar de uma manifestação artístico-cultural em que os protagonistas são homens, visto que ela utiliza como objeto de análise as mulheres subalternas. Nela nos referenciamos porque os mesmos marcadores que lançam as mulheres na subalternidade criam as subjetividades subalternas, que lançam as manifestações artísticos-culturais de Tradição Oral no campo do não saber, da não arte, do não conhecimento, da baixa cultura. Ou mesmo de uma cultura que deve ser analisada à luz da cultura de referência eurocentrada.

Para Spivak (2010), se para serem ouvidos os subalternos precisarem se utilizar de outros elementos culturais, linguísticos e em outros sistemas explicativos, nós (os subalternos), nunca seremos ouvidos. Essa mesma angústia de ter que falar em sistemas e signos que não são seus pode ser percebida no texto de Anzaldúa (2000, p. 229): "Nosso discurso também não é ouvido. Nós falamos em línguas, como os proscritos e os loucos. [...] Porque os olhos brancos não querem nos conhecer, eles não se preocupam em aprender nossa língua, a língua que nos reflete, a nossa cultura, o nosso espírito.” Contudo, Anzaldúa (2000, p. 230) nos apresenta uma maneira de resistir através das armas do opressor: "Eu, por exemplo, me tornei conhecedora e especialista em inglês, para irritar, para desafiar os professores arrogantes e racistas"18. E defende a escrita como ferramenta para resistir. "A escrita é uma ferramenta para penetrar naquele mistério, mas também nos protege, nos dá um distanciamento, nos ajuda a sobreviver"

${ }^{18}$ Glória Anzaldúa é filha de uma família de camponesas do sul do Texas, que tiveram suas famílias separadas por uma fronteira entre o México e Estados Unidos.

RIAEE - Revista Ibero-Americana de Estudos em Educação, Araraquara, v. 15, n. esp. 3, p. 2521-2537, nov., 2020. E-ISSN: 1982-5587 
(ANZALDÚA, 2000, p.232). Dessa forma, afirmamos que podemos usar as armas do colonizador como ferramenta para sobreviver, como a escrita que escrevemos agora. No entanto, a resistência fazemos no corpo, como disse o intelectual quilombola piauiense Antônio Bispo dos Santos (2019, p.33), que abriu este tópico: "Porque mesmo que queimem a escrita, não queimarão a oralidade”. E, como nos disse o mestre Griô Pedro, não tem como aprender a tradição nos livros, mas nos livros poderemos saber que existe mais de uma forma de pensar, que existem conhecimentos que se produzem na oralidade e que estes conhecimentos podem ser aprendidos no corpo.

\section{Considerações finais}

O silêncio é uma das condições da subalternidade, nisto Pollack (1989) e Spivack (2010) concordam. No entanto, as manifestações culturais de Tradição Oral podem ser um dos espaços para expressar essa voz "não-dita". Voz que fala através de saberes corporais, que cantam, que dançam e expressam seu cotidiano, suas memórias, seus mitos, seus gestos e sua ancestralidade. Portanto, a voz da cultura popular de Tradição Oral provoca um descentramento da cultura tida como cultura de referência, trazendo efeitos epistemológicos de consequências políticas; portanto, um espaço de enunciação da voz dos subalternos e um lugar de resistência política.

Os Embelêcos são a voz do povo do Capunga, em Moita Bonita, Sergipe. Todos os anos, no Sábado de Aleluia, há um rompimento da tristeza da Sexta Feira Santa com os Embelêcos, quando a alegria e o encantamento se revelam, carregam forças poderosas de dizer tudo o que não pôde ser dito, com sua língua, a da Tradição Oral.

A análise da brincança não se encerra neste artigo, sua potência também não cabe nestas folhas. Mas apresentá-la como possibilidade de reflexão e questionamento de onde estão as nossas vozes, as vozes subalternas, também nos proporciona refletir a importância da preservação dessas manifestações na concentração de esforços para a construção da poética e radical proposta de Quijano (2010), de “decolonizar o pensamento”. E, ao encerrar para continuar, convém pensar nas educações possíveis para possibilitar ao subalterno falar. Educações que nos permitam resistir e reiventar a forma de estar nos mundos e com os mundos.

AGRADECIMENTOS: Programa de Auxílio ao Professor Pesquisador PROAP/CAPES/2020. Processo 23113.019750/2020-19. 


\section{REFERÊNCIAS}

ALVES, A. C.; ROCHA, N. A. Diálogos (inter) culturais em educação e línguas: conceitos e discussões. Revista Ibero-Americana de Estudos em Educação, Araraquara, v. 14, n. 4, p. 2318-2332, out./dez. 2019. e-ISSN: 1982-5587. DOI:

https://doi.org/10.21723/riaee.v14i4.12193

ANDRADE, A. Fotografias dos embelêcos. 4 fotografias. Acervo pessoal do fotógrafo. $2016 ; 2017 ; 2019$.

ANDRADE, S. M. Embelêcos na mercedinha. 1 fotografia. 2015. Disponível em: https://www.facebook.com/photo.php?fbid=10206803187666370\&set=t.1847010351\&type= $3 \&$ theater. Acesso em: 6 jul. 2019.

APRENDIZ GRIÔ ROBERTO. Escrevivências. Anotações de conversa informal. Moita Bonita, SE, 28 jun. 2019.

ANZALDÚA, G. Falando em línguas: uma carta para as mulheres escritoras do terceiro mundo. Revista Estudos Feministas, Santa Catarina, v. 8, n. 1, p. 229-236, 2000.

BRANDÃO, C. R. O que é educação. São Paulo: Brasiliense, 2007.

LACOTIZ, A. Análise dos sufixos -ança/-ença, -ância/-ência na obra do simbolista João da Cruz e Souza. Estudos linguísticos XXXV, p.320-329, 2006.

LIMA, M. A.; COSTA, A. C. F. Dos gritos aos Griôs: a importância da oralidade para as tradições de matrizes africanas e indígenas no Brasil. Revista DIVERSITAS, São Paulo, ano 2, n. 3, p. 216-245.

MESTRE PEDRO. Escrevivências 1. Anotações de conversas informais tidas com o Mestre Griô Pedro. Povoado Capunga, Moita Bonita - SE. 29 de jun. de 2019.

MUNSBERG, J. A. S.; FERREIRA DA SILVA, G. Interculturalidade na perspectiva da descolonialidade: possibilidades via educação. Revista Ibero-Americana de Estudos em Educação, Araraquara, v. 13, n. 1, p. 140-154, jan./mar., 2018. E-ISSN: 1982-5587. DOI: https://doi.org/10.21723/riaee.v13.n1.2018.9175

PACHECO, E. F. H.; EYNG, A. M. A educação intercultural como possibilidade em processos decoloniais na garantia dos direitos da infância. Revista Ibero-Americana de Estudos em Educação, Araraquara, v. 15, n. 1, p. 110-124, jan./mar. 2020. e-ISSN: 19825587. DOI: https://doi.org/10.21723/riaee.v15i1.12370

PACHECO, L. Dossiê Pedagogia Griô: Escritas Griô. Revista DIVERSITAS, São Paulo, ano 2, n. 3, p. 22-99, set. 2014.

PACHECO, L. Rituais de vínculo e aprendizagem: aula espetáculo e Trilha Griô. Apostilha, 2017. 
PEREIRA, L. A. Nas trilhas de uma comunidade quilombola: tradição, oralidade, memória coletiva e identidade. Dissertação (Mestrado em Estudos Linguísticos) - Universidade Estadual de Feira de Santana, Feira de Santana, BA, 2014.

POLLACK, M. Memória, esquecimento, silêncio. Estudos Históricos, Rio de Janeiro, v. 2, n. 3, p. 3-15, 1989.

QUIJANO, A. Colonialidad del poder, eurocentrismo y América Latina. In: LANDER, E. (Comp.). La colonialidad del saber: eurocentrismo y ciencias sociales. Buenos Aires: Consejo Latinoamericano de Ciencias Sociales (Clacso), 2000.

RODRIGUES, P.; LEITE NUNES, A. Brincar: um olhar gestáltico. Revista de abordagem Gestáltica: phenomenological studies, v. XVI, n. 2. p. 189-198, dez. 2010. Disponível em: https://www.redalyc.org/pdf/3577/357735614009.pdf. Acesso em: 22 dez. 2019.

SANTOS, A. B. Colonização, quilombos: modos e significações. 2 ed. Brasília: Ayô, 2019.

SILVA, P. T. B. S. Diferença, interculturalidade e autossustentação na educação escolar indígena Pataxó. Revista Tempos e Espaços em Educação, São Cristóvão, n. 9, p. 101-112, jul./dez., 2012. ISSN: 1983-6597.

SIMAS, L. A.; RUFINO, L. Encantamento: sobre política de vida. Mórula Editorial. 2020.

SPIVAK, G. C. Pode o subalterno falar? Belo Horizonte: Editora UFMG, 2010.

\section{Como referenciar este artigo}

SANTANA, L.; LUCINI, M. A brincança dos Embelêcos: vozes políticas e epistemológicas dos subalternos. Revista Ibero-Americana de Estudos em Educação, Araraquara, v. 15, n. esp. 3, p. 2521-2537, nov., 2020. E-ISSN: 1982-5587. DOI: https://doi.org/10.21723/riaee.v15iesp3.14455

Submetido em: 20/07/2020

Revisões requeridas em: 30/08/2020

Aprovado em: 29/09/2020

Publicado em: 30/10/2020 